\title{
O CONCEITO DE IMITAÇÃo NO JovEM FRIEDRICH SCHLEGEL ${ }^{1}$
}

\author{
Silvia Faustino ${ }^{2}$
}

\begin{abstract}
RESUMO: Tomando por base o ensaio Über das Studium der griechschen Poesie (Sobre o estudo da poesia grega), este trabalho tem por objetivo investigar o conceito de imitaçáo no pensamento do jovem Friedrich Schlegel. Além de explicitar dois usos distintos do conceito - que aparece ora como imitação do real, ora como imitação dos antigos - pretende-se identificar oscilações e tensôes terminológicas que possam esclarecer a postura filosófica do autor, frente à profunda crise de legitimidade, que, naquela época, atinge a concepção da arte como imitação da natureza. É intenção mostrar que, embora reconheça os aspectos negativos que a má aplicação do modelo clássico provoca na produçấo e na teoria da arte moderna, Schlegel também propóe um sentido positivo, à luz do qual a imitaçáo pode ser harmonizada com os princípios filosóficos basilares de uma estética idealista de feiçáo kantiana.
\end{abstract}

PALAVRAS-CHAVE: Friedrich Schlegel. Imitaçăo. Poesia. Modernidade.

\section{I}

O ensaio Über das Studium der griechschen Poesie (Sobre o estudo da poesia grega), produzido entre 1795 e 1796, é uma obra de juventude Friedrich Schlegel tinha apenas vinte e três anos, quando o escreveu - e hoje ocupa um lugar de destaque nos estudos sobre a formação do vocabulário moderno da crítica estética. ${ }^{3}$ Inserido na tradição do idealismo alemão póskantiano, e tomando alguns de seus resultados como base, o ensaio investiga sob quais condiçóes a poesia grega - que atingiu a suprema forma da arte em sua época clássica - pode ser considerada como modelo para a poesia moderna. Assumindo no campo da poesia um desafio similar ao que Winckelmann teria enfrentado, décadas antes, no campo da pintura e da escultura, Schlegel buscará esclarecer e criticar a situação da arte do seu tempo, por meio de uma

\footnotetext{
${ }^{1}$ Este artigo resulta de pesquisa financiada pela CAPES - Coordenação de Aperfeiçoamento de Pessoal de Nível Superior.

http://dx.doi.org/10.1590/S0101-31732016000500003

${ }^{2}$ Doutorado em Filosofia pela Universidade de São Paulo (USP) e Pós-Doutorado pela HumboldtUniversität, de Berlim. Professora no Departamento de Filosofia e no Programa de Pós-Graduação em Filosofia na Universidade Federal da Bahia (UFBA). silviassisaes@gmail.com.

${ }^{3} \mathrm{O}$ prefácio foi escrito em 1797 , data de sua publicaçăo; doravante, essa obra será referida apenas como Studium.
} 
reflexão sobre a arte grega, o que o levará a realçar a fecundidade natural do espírito clássico genuíno dos gregos antigos contra o classicismo infrutífero que vê alastrado, na prática e na teoria de sua época. Como bem observa Peter Szondi (1992, p. 62), na sucessão dos escritos de Winckelmann, Herder, Moritz e F. Schlegel, é possível vislumbrar a continuidade e a mudança de uma problemática estética que toma como ponto de partida as relaçóes entre a antiguidade clássica e a modernidade. ${ }^{4}$ No entanto, aprofundar, com o cuidado merecido, as linhas que ligam as teses de Schlegel aos escritos fundamentais desses outros autores é empreendimento que supera o escopo deste trabalho, cuja pretensão se limita ao esforço de tentar reunir, de maneira mais organizada e consistente, as notas características que o conceito de imitação recebe, ao longo do ensaio. Tal investigação mostrará que não há um posicionamento teórico único e que as exploraçóes conceituais se iluminam sob diversos ângulos, não sendo possível caracterizá-las em termos de uma simples recusa ou defesa do princípio de imitação. Por essa razão, este artigo busca realçar o teor filosófico das oscilaçôes e tensôes terminológicas que marcam a posição do autor, frente à profunda crise de legitimidade pela qual passa a concepção da arte como imitação. Além de explicitar dois usos distintos do conceito - que aparece ora como imitação do real, ora como imitaçáo dos antigos -, pretende-se demonstrar que, embora reconheça os aspectos negativos que a má aplicação do modelo clássico provoca na produção e na teoria da arte moderna, Schlegel também propóe um sentido positivo, pelo qual a imitação pode ser harmonizada com os princípios filosóficos basilares de uma estética idealista de feição kantiana.

Antes de mais nada, é preciso convir que a confusão conceitual em torno da noçáo mais estrita de imitação vem de longe. De acordo com Stephen Halliwell, em seu livro The Aesthetics of Mimesis (2002, p. 343), durante todo o período que vai do classicismo renascentista ao neoclassicismo (do século XV ao XVIII), os termos "imitação" e "representação" são considerados intercambiáveis; e, no século XVIII, há uma justaposição semântica entre "imitação" e "expressão", a qual pode ser encontrada tanto em textos de Charles Batteux e de Denis Diderot, quando tratam da música (HALLIWELL, 2002, p. 236, nota 5) quanto no Laocoonte, de G. E. Lessing, quando esse autor exemplifica um modo pelo qual a noção de imitação se combina com os conceitos de imaginaçãa e de expressão (HALLIWELL, 2002, p. 360, nota

${ }^{4}$ J. J. Winckelmann (1717-1768); J. G. Herder (1744-1803); K. P. Moritz (1756-1793); F. Schlegel (1772-1829). 
36). Ou seja, pode-se sustentar que, no decorrer de um bom trecho do século XVIII, há sinais claros de uma interação entre os significados de "imitação", "expressão" e "representação". Mas a relação que nos interessa de perto - e que é diretamente tematizada no ensaio de Schlegel - é aquela que se verifica entre "imitação" [Nachahmung] e "representação" [Darstellung]. Ao acompanharmos seu esforço para elucidar esse vínculo conceitual, veremos o quanto ele ainda está longe de separar radicalmente essas duas ideias, como o próprio Halliwell (2002, p. 364, nota 46) afirma ter ocorrido com Hegel, o qual, após fazer uma crítica mordaz ao conceito de imitação, prefere continuar discutindo a arte somente em termos de representação.

A falta de clareza do conceito - insistamos - vem de longe, mas parece intensificar-se diante do preceito neoclássico da arte como "imitação da bela natureza", estabelecido por Charles Batteux, no livro As belas artes reduzidas a um mesmo princípio, e cuja recepção na Alemanha mereceria, por si só, um estudo à parte. Importa, no entanto, mencionar J. C. Gottsched, que se filiava ao ideário estético de Batteux e era considerado como autoridade máxima nos assuntos literários, gozando de grande prestígio até o fim da primeira metade do século XVIII, tendo sido, inclusive, professor do teórico e crítico literário Elias Schlegel, tio de Friedrich e de August. Salientemos, grosso modo, apenas o seguinte: em Gottsched, a palavra "imitaçáo" designa quer uma mera cópia, quer uma ação de formar ou de modelar conforme à natureza, quer mesmo uma total invenção. Quanto à noção da "natureza” a ser imitada, esta se explicita ora como bela, ora como racional, ora como algo bem conhecido, além de ocasionalmente significar simplesmente a verdade; e, quando se refere aos "objetos" da imitação, Gottsched parece querer dizer que eles variam entre a natureza, a verdade e a razão. ${ }^{5}$

É, portanto, no enfrentamento de um conceito em fervorosa disputa filosófica-e aqui não podemos deixar de mencionar as críticas de AdolfSchlegel (o pai de August e Friedrich) a Batteux - que Winckelmann defende as obras gregas como um ideal de beleza a ser imitado; e que o jovem Schlegel tenta preservar um significado positivo para o conceito, a fim de mantê-lo de certo modo inserido no novo vocabulário da arte e da crítica. Perto do fim do texto do Studium, ele assume que a imitação dos gregos é um elemento essencial do projeto estético que propóe para a modernidade; e que as condiçóes necessárias

\footnotetext{
5 Tais afirmações são todas baseadas nas análises de E. A. McCormic (1965, p. xviii) e de E. M. Wilkinson (1973, p. 24), que se referem à obra Versuch einer Critischen Dichtkunst vor die Deutschen, de J. C. Gottsched, publicada pela primeira vez em 1751.
} 
para que se restabeleça a tão venerada e já desaparecida bela-arte são uma "[...] ciência universalmente válida do belo e da representação [Darstellung]" e uma "[...] correta imitação dos protótipos gregos" (SCHLEGEL, 1967, p. 354). Ora, o que Schlegel entende por "imitação" e em que sentido a imitação dos gregos pode ser "correta"?

\section{II}

Na opinião de Luiz Costa Lima (2000, p. 60), Schlegel é "um autor insuspeito de simpatias pela mímesis", e, nessa mesma linha, Lacoue-Labarthe (2001, p. 16) comenta a preocupação que ele teve em restituir ao conceito de mímesis o seu "significado pretensamente autêntico", isto é, não depreciativo nem pejorativo. Em sintonia com esses pensadores que, infelizmente, não aprofundam suas afirmaçóes, chamo a atenção para um trecho que confirma a acolhida positiva que Schlegel dá ao clássico conceito e que comprova uma intenção nítida de iluminar a antiga noção com novos horizontes de significação:

O nome "imitação" é desde logo insultuoso e estigmatizado por todos aqueles que se creem gênios originais. Entende-se por esse nome a violência que a natureza grande e forte exerce sobre o impotente. Náo conheço, porém, outra palavra senão imitação, para designar a ação daquele que - seja artista ou conhecedor da arte - se apropria da legalidade daquele protótipo sem se deixar limitar pela particularidade que a forma exterior - o invólucro do espírito universal - possa, contudo, sempre comportar. É óbvio que essa imitaçáo é absolutamente impossível sem a mais elevada autonomia. Falo daquela comunicaçáo do belo pela qual o conhecedor entra em contato com $\mathrm{o}$ artista, e o artista com a divindade, tal como o ímã que não só atrai o ferro como também, através do seu contato, comunica-lhe a força magnética. (SCHLEGEL, 1967, p. 274-275, tradução nossa). ${ }^{6}$

Esse trecho é importante, porque mostra o esforço de combinar a noção de imitação da natureza com uma estética da autonomia criadora; e isso depois de Kant ter proscrito a imitação da dimensão da arte genial. Infelizmente, Schlegel não aprofunda, nesse momento do texto, a relação entre a imitação e "a mais elevada autonomia”, de modo que será preciso buscar o sentido dessa passagem, a partir de sua possível ligaçáo com outras teses apresentadas ao longo do texto. Nessa espécie de transposição da imitação para o contexto idealista, o problema não parece estar na existência de um protótipo [Urbild] nem tampouco no fato

\footnotetext{
${ }^{6}$ Esta e as demais traduções do texto do Studium são de minha autoria.
} 
de que ele tenha suas leis, mas sim na forma necessária de se lidar com essas leis: a imitação ocorrerá na chave da mais elevada autonomia se - e somente se - o artista puder apropriar-se da legalidade do seu protótipo. Fica claro, portanto, que não se trata de recusar a relação entre arte e lei, mas de buscar uma correta visão dessa espécie muito particular de vínculo. No parágrafo anterior ao citado, ao negar que a suma beleza possa ser produzida pelo conceito de bom gosto e de estilo perfeito, Schlegel assevera que, no artista, a lei deve se tornar uma "inclinaçáo", porque, na vida que vem da vida e na força que produz força, "a lei pura é vazia" - e, a fim de que possa preenchê-la e aplicá-la, o artista necessita de um "protótipo estético supremo" para ter uma "intuiçấo" na qual a lei se torne como que visível (SCHLEGEL, 1967, p. 274).

$\mathrm{Na}$ medida em que o artista toma para si e atualiza em si a potência geradora do belo que opera no protótipo, ele náo é "impotente" diante de uma natureza que o constrange. A autonomia pressupóe o vazio - o ponto zero da legalidade, porque a lei só pode ser intuída como que em estado puro e antes de ser aplicada. Importante enfatizar que a legalidade a ser intuída náo é intrínseca ao ânimo humano e nem exclusivamente imanente ao protótipo (sobretudo em sua forma exterior). A apropriação intuitiva da legalidade do protótipo só será possível se ele mesmo se constituir no regime de uma "livre legalidade" (SCHLEGEL, 1967, p. 346-7) e, por isso, a imitação compatível com a "mais elevada autonomia" será também a única capaz de “apropriar-se da objetividade” do protótipo (SCHLEGEL, 1967, p. 331). No conceito de apropriação da legalidade do protótipo não há, pois, lugar nem para o objetivismo do protótipo nem para o subjetivismo do artista: não há determinação transitiva nem do artista para o protótipo e nem do protótipo para o artista. Esse é o sentido de dizer que a legalidade a ser intuída é livre, e livre também será o modo de plasmá-la numa forma exterior, para que possa ser novamente intuída, e assim sucessivamente. ${ }^{7}$

Tudo leva a crer, portanto, que o conceito de imitação em Schlegel implica a existência (conceitualmente vaga) de um "protótipo", e isso parece valer tanto para a "imitação dos antigos" quanto para a "imitação do real" (SCHLEGEL, 1967, p. 289). Esta última noção surge no contexto no qual se discute a arte como instância possível e necessária da manifestação sensível do espiritual. Como reconhece Schlegel, o espiritual tem necessidade de

\footnotetext{
${ }^{7}$ Não há lugar nem para a heteronomia estética do classicismo, nem para o determinismo subjetivista. Essa análise está de pleno acordo com a valiosa observação de Szondi de que o Studium é uma "tomada de posição", seja em relação ao Sturm und Drang, seja em relação ao classicismo (SZONDI, 1992, p. 72).
} 
aparecer sensivelmente, do mesmo modo que o ânimo humano livre tem necessidade do elemento empírico de uma organização animal para existir. O contexto dessas consideraçóes é a defesa da possibilidade de um "infinito aperfeiçoamento", tanto para a "apariçẫo sensível do espiritual” quanto para a "imitação do real". A imitação do real pode aperfeiçoar-se infinitamente, porque "[...] a plenitude de cada coisa individual é inesgotável, e nenhuma imagem jamais pode passar a ser o seu protótipo." (SCHLEGEL, 1967, p. 289). Ou seja, o aperfeiçoamento infinito repousa na impossibilidade de a representação do real alcançar a plenitude do seu protótipo. Por outro lado, a apariçáo sensível do espiritual se aperfeiçoa ao infinito, no sentido de que ela pode se tornar "[...] sempre mais viva, mais determinada e mais clara, sem poder jamais alcançar completamente seu fim." (SCHLEGEL, 1967, p. 289). E isso tem de ser assim porque, se o fim pudesse ser alcançado numa aparição, "o universal, que deve aparecer no individual", teria de "transformar-se ele próprio em individual”; mas isso é impossível, garante Schlegel (10967, p. 289), porque ambos estão separados por um "abismo infinito".

Aqui, é fundamental reter a premissa de que o universal se orienta na direção de um fim. Ora, o fato de que ele apareça no individual não implica que ele tenha alcançado seu fim, pois, se assim fosse, o universal se confundiria com o próprio individual no qual aparece. Entendamos agora a analogia: assim como o universal não alcança seu fim no individual em que aparece, a representação de cada coisa real não esgota a plenitude desta. Assim como o universal não cabe no individual, o protótipo ou plenitude de cada coisa náo cabe numa representação dela. Do ponto de vista dessa estética, a manifestação do espiritual e a representação da plenitude de cada coisa só se realizam num processo de aperfeiçoamento infinito, cujo protótipo é, em sua completude, inatingível. O aperfeiçoamento infinito só pode se dar na dimensão de um processo teleológico, cujo sentido não pode estar numa imitação particular e localizada.

\section{III}

Uma das teses centrais do Studium é a afirmação da "artificialidade da formação [Bildung] estética moderna". Como o texto mostra, em vários momentos, a principal razão dessa artificialidade está na "predominância do individual, do característico e do filosófico" em todo o conjunto da poesia e da arte modernas (SCHLEGEL, 1967, p. 241). Movido pelo propósito de defender que as obras de arte constituídas à luz desses interesses não mereceriam ser inseridas no domínio legítimo da bela-arte, Schlegel procura traçar uma 
distinção entre "arte que representa/representativa" [darstellenden Kunst] e "bela-arte" [schöne Kunst], a fim de que o território desta última possa ser mais bem delimitado. De acordo com ele, a tendência da época era restringir demais o campo da arte representativa e ampliar demais o domínio da bela-arte, e essa confusão de domínios não apenas provocava, como também intensificava a formação ou cultura artificial.

Para Schlegel, a arte representativa compreende um grande gênero, cujo caráter específico consiste, de um modo geral, na "idealidade da representação"; ele esclarece que, por "representação ideal”, entende aquela na qual "[...] a matéria representada é escolhida e ordenada e, quando possível, também formada conforme as leis do espírito que representa." (SCHLEGEL, 1967, p. 242). Ora, é crucial observar que, no próprio momento em que se esclarece o conceito de representação ideal, a "descrição" e a "imitação" são admitidas como "órgãos" dessa espécie de representação. Quanto à bela-arte, ele afirma simplesmente que o seu "caráter específico" é "o livre jogo sem um fim determinado" (SCHLEGEL, 1967, p. 241-242). Ora, nessa frase (que ressoa como suma lapidar de ensinamentos básicos da Crítica do Juizo, de Kant), é importante notar que "livre jogo sem fim determinado" é a expressão que designa justamente o traço que distingue o tipo específico de idealidade ligada à bela-arte daquela idealidade mais geral associada à arte representativa.

Neste ponto, é preciso convir que não é muito claro o que Schlegel chama de "idealidade da representação". O que se pode com certeza afirmar é que ela comporta graus e valores contínuos que vão desde a escolha da matéria a ser representada, passando por sua ordenação, até o grau máximo: sua formação. E o problema suplementar consistiria em saber até que ponto uma representação ideal poderia ser vista como bela-arte, isto é, se entre a belaarte e a arte representativa há apenas uma diferença de grau ou se há um corte essencial entre os dois domínios, havendo entre eles, portanto, uma diferença de natureza. Atentemos agora para a seguinte afirmação feita neste parágrafo:

Há conhecimentos que não podem ser comunicados nem por meio de imitaçấo histórica nem por meio de descrição intelectual, mas tãosomente apresentados como intuiçóes ideais individuais, como exemplos e evidências de conceitos e ideias. (SCHLEGEL, 1967, p. 242).

A questão, nessa passagem, diz respeito à capacidade de comunicar conceitos e ideias por meio de apresentaçôes intuitivas, isto é, representaçóes 
nas quais tais conceitos e ideias possam ser intuídos. Notemos que à imitação - qualificada de "histórica" e aproximada da "descrição intelectual" - é negado o poder de veicular conhecimentos intuitivos. Nesse sentido, é claro que a imitação não somente está longe do "livre jogo sem um fim determinado" que caracteriza a bela-arte, como também está muito longe daquela imitação que vimos vinculada à "mais elevada autonomia". Isso indica que o conceito de imitação em Schlegel é flexível e elástico e assume diferentes significados, conforme o contexto em que é empregado. A prova decisiva disso está no seguinte: em uma longa nota pertinente ao trecho que estamos analisando, Schlegel reduz a imitação a mero "instrumento" da representação científica e a expulsa do próprio campo das representaçôes ideais:

[...] a representaçáo científica - quer seu instrumento seja descrição arbitrária ou imitação figurativa - se diferencia da representação da arte pelo fato de que, embora ordene o dado segundo leis do espírito que representa, raramente ela escolhe a matéria, jamais a forma ou a inventa. Numa palavra, ela não é ideal. (SCHLEGEL, 1967, p. 242-243, nota).

Estamos aqui diante de um outro limite: a representação que só ordena a matéria deixa de ser ideal. Só é ideal - ou possui um mínimo grau de idealidade - a representação capaz, em alguma medida, de escolher, formar ou inventar a matéria que representa: quanto mais ela for capaz de produzir a sua própria matéria, mais ideal, mais autônoma e, consequentemente, mais bela ela será.

Num momento posterior do ensaio, Schlegel especifica o que ele chama de "arte representativa livre", que, segundo ele, se compóe de "duas leis técnicas absolutas": a "sensibilização do universal" e a "imitação do individual". 8 Depois de afirmar que não há limite para o aperfeiçoamento desses dois componentes, alerta para o seguinte: "A meta da arte representativa livre é o incondicionado; o individual não deve por si só ser um fim (Subjetividade)." (SCHLEGEL, 1967, p. 291). Tudo indica que o individual não pode ser um fim pela essencial subjetividade que caracterizaria a sua forma condicionada, pontual e localizada. Ora, é justamente nesse ponto do texto que encontramos uma explicitação do conceito de objetividade, tão importante no Studium. “Objetividade”, escreve Schlegel (1967, p. 291), “[...] é a expressão mais

\footnotetext{
${ }^{8}$ Há uma relação interna entre "sensibilizaçăo do universal" e "aparição sensível do espiritual" (SCHLEGEL, 1967, p. 289), assim como entre "imitação do individual" e "imitação do real" (SCHLEGEL, 1967, p. 289).
} 
adequada para essa relação conforme à lei do universal com o individual na representaçáo livre.” A objetividade designa, portanto, uma espécie de interrelação ou proporção regulada entre o individual e o universal. Considero como digno de nota o fato de Schlegel conceituar a objetividade utilizando os mesmos termos - ou termos muito próximos - aos que Kant emprega, quando elabora o seu conceito de juízo reflexionante, isto é, o juízo em que só o "particular" é dado, tendo o "universal" de ser encontrado (KANT, 1993, p. 23). Mas, se é permitido presumir que o "individual" ou "característico" de Schlegel pode ser aproximado do "particular" de Kant, temos de convir também que a objetividade, tal como entendida por Schlegel, exige a efetivação daquilo que Kant chama de reflexão (e que, em sentido estrito, implica o caminho que vai de um particular dado em busca de um universal não determinado). ${ }^{9}$ Contudo, é preciso todo o cuidado com essa aproximação entre a noção kantiana de reflexão e a noção schlegeliana de objetividade, pois ela tem um limite claro: em Schlegel, o caráter (digamos) reflexionante da objetividade do espírito será impossível sem o sentido radicalmente histórico de um processo progressivo de aperfeiçoamento infinito - caso em que a reflexão teria de ser perpassada pela história.

À luz dessas consideraçôes, torna-se mais fácil entender as razões que levam Schlegel a recusar toda e qualquer visão que fundamente a arte numa concepção realista da verdade. Logo depois da explicação sobre a objetividade, ele afirma que as obras de arte particulares não estão de modo algum concatenadas às "leis da realidade" e que o limite de cada uma delas está em suas próprias "leis de possibilidade interna" (SCHLEGEL, 1967, p. 292). Isso indica claramente que a objetividade da arte livre não se funda na legalidade da realidade - o que levaria à heteronomia estética - e sim na simples concordância da obra consigo mesma, sendo suas leis internas suficientes para impedir as contradições internas (obviamente indesejáveis).

Schlegel adverte que prefere chamar as "leis de possibilidade interna" de "correção técnica" e não de "verdade", justamente porque este último termo "lembra demais as leis da realidade" e a "fidelidade copista" do artista escravo, o qual "[...] só imita o individual." (SCHLEGEL, 1967, p. 292). Como ele ressalta, a correção técnica pode, inclusive, exigir - como ocorre na tragédia pura ou na comédia pura - um "desvio ideal" em relação àquilo que "[...] na realidade é verdadeiro e verossímil.” (SCHLEGEL, 1967, p. 292, nota). Ora,

${ }^{9}$ A questão de saber como a universalidade subjetiva, a qual fundamenta a reflexão em Kant, se compara à objetividade do espírito representante em Schlegel é tema que supera o âmbito deste trabalho. 
o conceito de correção técnica assim caracterizado está em perfeita harmonia com o programa de uma estética idealista que valoriza a obra de arte por sua legalidade autônoma. É bem este o caso de uma correção técnica que prescinde totalmente da figura de um "entendimento condutor" (SCHLEGEL, 1967, p. 293), o qual também é "isolador" e atua de modo a segregar e individualizar "o todo da natureza” (SCHLEGEL, 1967, p. 245). A preponderância de um entendimento preso a funçóes meramente analíticas seria um entrave à apreensão daquilo que somente a ação conjunta das múltiplas faculdades do espírito pode realizar. Schlegel $(1967$, p. 245$)$ estabelece, portanto, uma clara e estreita relação entre o "entendimento que isola" e a "[...] imitação fiel do individual”, que não consegue passar de "mera habilidade de copistas."

Por aí também se entende a crítica mordaz a certa "teoria aplicada da poesia" que, buscando a finalidade da arte no "encanto", na "correçáo" e na "verdade", acabou legitimando certas obras como "eternos modelos de imitação" - o que só contribuiu para que se consolidasse o que já se praticava equivocadamente (SCHLEGEL, 1967, p. 220-221). Com o selo de sua autoridade, essa teoria teria prejudicado a formação do gosto e colaborado de maneira decisiva para o desventurado desenrolar da história da arte. Schlegel não partilha da ideia de que o "digno de imitação" na poesia grega seja privilégio de uns "poucos gênios eleitos"; o "meramente individual" não é digno de imitar-se, justamente porque somente o "universal" pode ser a "lei e o protótipo" para todos os tempos e povos. É nesse sentido que a beleza grega, na qualidade de um bem comum do gosto público, só pode ter o seu espírito capturado no seu conjunto (SCHLEGEL, 1967, p. 282). Em razáo do apego ao individual, os modernos haviam imitado até então apenas o "individual das formas gregas", como se fosse fácil separar naquela arte a "forma local" do "objetivo" que a ultrapassa (SCHLEGEL, 1967, p. 331). Mas essa separação, admite Schlegel, é "infinitamente difícil”, na medida em que, na poesia grega, "[...] o objetivo se propaga até os mais finos ramos da frondosa árvore”, estando presente como "elemento e órgão" em todas as instâncias em que se mistura com o individual. A imagem da árvore ilustra a unidade orgânica entre o individual-local e o objetivo-universal, cuja efetividade supera a localização espaço-temporal do modelo tomado como exemplar. É assim que Schlegel (1967, p. 331, grifo do autor) conclui, ressaltando que "[...] só pode imitar a poesia grega aquele que a conhece por inteiro", isto é, "só a imita realmente" aquele que "se apropria da objetividade" de todo o seu conjunto. A imitação correta dos gregos reside na possibilidade de apropriar-se de sua objetividade, isto é, do espírito encarnado em todo o conjunto - e é óbvio que esse fim está 
completamente vedado aos procedimentos segregativos da imitação moderna das formas individuais. O "objetivo" nada tem a ver com a forma, nem com o conteúdo do individual.

O problema da imitação dos antigos reside na "[...] maneira e no método da imitação" (SCHLEGEL, 1967, p. 331). É preciso que não se imite "isto ou aquilo", ou um "único poeta preferido", ou uma "forma local" ou "órgão individual', pois "[...] jamais um individuo enquanto tal pode ser norma universal." (SCHLEGEL, 1967, p. 346, grifo do autor). Mais uma vez se salienta a necessidade de o poeta moderno "apropriar-se" da "livre regularidade" e da "objetividade da representação", as quais favorecem a captação do espírito liberal, da riqueza ética e da bela simetria que estão mais ou menos dispersos em todo o conjunto da poesia grega. Somente nesse ato de apropriaçáo pode o poeta moderno visualizar o "espírito do todo" e, enfim, a "pura grecidade". Para "imitar corretamente" a poesia grega, é preciso conhecê-la e entendê-la de verdade; a explicação filosófica e a apreciação estética dessa poesia exigem o seu estudo como um todo, sem negligenciar a cultura natural dentro da qual surgiu. Para isso, são necessários princípios e conceitos científicos de uma "filosofia objetiva da história" e de uma "filosofia objetiva da arte": somente por essa via seria possível buscar e encontrar o organismo da poesia e, com isso, também os rumos legítimos da arte e de uma teoria crítica da arte de que a modernidade tanto precisa (SCHLEGEL, 1967, p. 346-347).

\section{IV}

Numa de suas afirmaçóes mais contundentes do Studium, Schlegel (1967, p. 222) assinala que "[...] a ausência de caráter parece ser o único caráter da poesia moderna”. Ora, é notável como o método equivocado e parcial de imitaçáo conduz, na teoria e na prática da arte, a esse estado de penúria da poesia moderna. $\mathrm{O}$ problema da teoria começa com a exigência de uma "absoluta originalidade" dos modelos erigidos como medida suprema do valor artístico, de um lado, e, de outro, a condenaçáo à "infinita desonra" de todas obras sobre as quais paire a menor suspeita de imitaçáo. Trata-se de uma forma perversa de conceber a arte, na medida em que "um bando de copistas mais mesquinhos" se aplica a seguir todo grande artista original em incontáveis repetiçôes que deformam e deturpam a tal ponto "o grande protótipo", que este acaba se convertendo em algo banal e repulsivo. No limite, a esse "endeusamento" inicial segue-se o "horror" e até mesmo o "eterno 
esquecimento" (SCHLEGEL, 1967, p. 222). A "ânsia pela originalidade”, que conduz à confusão entre o belo e o "interessante", ${ }^{10}$ está na raiz desse paradoxo que acaba destituindo de valor os próprios modelos eleitos como originais.

A "ausência de caráter" da poesia moderna tem um outro aspecto paradoxal. No contexto da discussáo acerca da "formação" [Bildung] da poesia moderna, Schlegel chama a atenção para o fato de que, desde o Renascimento, há uma "constante imitação recíproca das poesias nacionais", isto é, uma espécie particular de reciprocidade de influência entre as "maneiras" italiana, francesa e inglesa. ${ }^{11}$ A cada momento, afirma Schlegel, uma delas teve seu auge e dominou o gosto europeu cultivado, com uma ressalva: a Alemanha seria a única que apenas sofreu as influências externas, sem ter oferecido nada em contrapartida. ${ }^{12}$ E isso teria acontecido, porque a "forte dureza do caráter nacional original" do povo alemão foi se diluindo, se desbotando, até que, por fim, esse caráter foi quase extirpado e, em seu lugar, apareceu um "caráter geral europeu." (SCHLEGEL, 1967, p. 226). A "imitação recíproca” das maneiras é concebida, portanto, como uma "associaçáo" na qual o aspecto original e nacional da poesia se esvanece numa gradual "transição" que vai dando lugar ao abstrato "caráter geral europeu”, o qual, para Schlegel (1967, p. 226), nada mais é do que a própria "formação artificial" da poesia moderna. Ora, a gradual eliminação do caráter nacional em nome de um caráter geral é bem o exemplo de como a imitação do individual ou do característico - representado aqui pelas "maneiras" - conduz a uma generalidade ou universalidade amorfa e sem representatividade artística efetiva. O paradoxo da imitação recíproca do característico das poesias nacionais está na perda desse característico e na concomitante destruição da possibilidade de se chegar a um universal concreto e objetivo.

De acordo com o percurso até aqui realizado, pode-se concluir que a noçãa de imitação é trabalhada sob dois aspectos relevantes, no Studium: ora ela aparece como meio e órgão da arte representativa em geral; ora, como imitação dos antigos. Quanto ao primeiro aspecto, que poderíamos qualificar como o mais técnico do ponto de vista vocabular, o conceito de imitação ocupa o amplo território das artes representativas e, com relativa flexibilidade, acompanha toda a sua extensão, a qual inclui desde a "imitação figurativa",

\footnotetext{
${ }^{10}$ Entendo "interessante" como conceito aproximado dos conceitos de "individual" e "característico". Sobre esse conceito, recomendo o artigo de Arlenice Almeida Silva, "O interessante em Friedrich Schlegel" (indicaçóes bibliográficas no final).

${ }^{11} \mathrm{O}$ termo original é "maneira" [Manier] (p. 226), e não "estilo", tal como consta nas traduçôes francesa e espanhola.

${ }^{12}$ É certo que, lá pelo fim do Studium, Goethe figurará como uma honrosa exceção.
} 
que, enquanto representação científica, perde o caráter ideal; a imitação histórica; a imitação do real e do individual - que contêm a possibilidade de um aperfeiçoamento infinito -; até a "arte representativa livre" e aquela imitação vinculada à "mais elevada autonomia”, ponto este em que já se daria a passagem - e não o corte - para o domínio das belas artes. Quanto ao segundo aspecto, a imitação dos antigos aparece ao mesmo tempo como a causa e como a solução dos problemas mais urgentes da arte, na modernidade, tudo ficando a depender de ser ela corretamente concebida como um protótipo libertador. Em ambas as perspectivas, a "imitação do individual”, que não pode efetivar a manifestação do universal, do espiritual e do objetivo, é condenada.

FAUSTINO, Sílvia. The concept of imitation in the young Friedrich Schlegel. Trans/Form/ Ação, Marília, v. 39, p. 23-36, 2016. Ediçăo Especial.

\begin{abstract}
On the basis of the essay Über das Studium der griechschen Poesie (On the Study of Greek Poetry), this work intends to investigate the concept of imitation in the thought of the young Friedrich Schlegel. In addition to pointing out two different uses of this concept - which appears either as imitation of the real or as imitation of the ancients - it is our aim to identify alternations and terminological tensions that might illuminate the author's philosophical position regarding the deep legitimacy crisis which, at the time, hounded the concept of art as imitation of nature. It is our intention to show that, although Schlegel did recognize the negative effects of the thoughtless employment of the classical model on the theory and practice of modern art, he also put forward a positive sense in which imitation could be harmonized with the founding philosophical principles of an idealist Kantian-like aesthetics.
\end{abstract}

KEYWORDS: Friedrich Schlegel. Imitation. Poetry. Modernity.

\title{
REFERÊNCIAS
}

BATTEUX, C. As belas artes reduzidas a um mesmo princípio. Tradução de Natália Maruyama e Adriano Ribeiro. Apresentação e notas de Marco Aurélio Werle. Sáo Paulo: Humanitas, 2009.

COSTA LIMA, L. Mimesis: desafio ao pensamento. Rio de Janeiro: Civilização Brasileira, 2000.

HALLIWELL, S. The aesthetics of mimesis. Ancient texts and modern problems. Princeton e Oxford: Princeton University Press, 2002.

KANT, I. Crítica da faculdade do juizo. Tradução de Valerio Rohden e António Marques. Rio de Janeiro: Forense, 1993. 
LACOUE-LABARTHE, P. A vera semelhança. In: DUARTE, R.; FIGUEIREDO, V. (Org.). Mimesis e expressäo. Belo Horizonte: Editora da UFMG, 2001. p. 16.

MCCORMIC, E. A. Translator's introduction. In: On imitation and other essays: Johann Elias Schlegel. New York: The Library of Liberal Arts, 1965. p.

SCHLEGEL, F. Über das studium der griechschen Poesie. In: BEHLER, E. (Org.). Studien des klassischen altertums. Kritische Friedrich Schlegel Ausgabe (v. I). Paderborn; Munique; Viena: Ferdinand Schöningh, 1967. p. 29-63.

. Sur l'étude de la poésie grecque. Traduit et présenté par Marie-Laure Monfort. Paris: Éditions de L'Éclat, 2012.

. Sobre el estúdio de la poesia griega. Traducción Berta Raposo. Madrid: Ediciones Akal, 1996.

SILVA, A. A. O interessante em Friedrich Schlegel. Trans/form/ação, Marília, v. 34, n. 2, p. 75-94, 2011.

SZONDI, P. Poética y filosofia de la historia I: antigüedad clássica y modernidad em la estética de la época de Goethe: la teoria hegeliana de la poesia. Traducción Francisco L. Lisi. Madrid: La Balsa de la Medusa, 1992.

WILKINSON, E. M. Introduction. In: Johann Elias Schlegel: a German Pioneer in Aesthetics. Darmstadt: Wissenschaftliche Buchgesellschaft, 1973. p. i-v.

Recebido / Received: 08/06/2016

Aprovado / Approved: 04/08/2016 